\title{
Misoprostol versus Letrozol with Misoprostol in Management of First Trimesteric Missed Miscarriage
}

\author{
*Corresponding Author: \\ Abd Elazeem Mohammed Afifi \\ znaty2018@yahoo.com
}

Abd Elazeem Mohammed Afifi ${ }^{1, *}$ M.B.B.CH, Farid Ibrahim Hassan ${ }^{2}$ MD, Mofeed Fawzy Mohammed ${ }^{2}$ MD

Received for publication August 16, 2021; Accepted October 18, 2021; Published online October 18, 2021.

Copyright The Authors published by Al-Azhar University, Faculty of Medicine, Cairo, Egypt. Users have the right to read, download, copy, distribute, print, search, or link to the full texts of articles under the following conditions: Creative Commons Attribution-Share Alike 4.0 International Public License (CC $B Y-S A$ 4.0)

doi: 10.21608/aimj.2021.89692.1545

${ }^{I}$ Risedent of Obstetrics and Gynecology Department, Luxor General Hospital, Egypt.

${ }^{2}$ Obstetrics and Gynecology Department, Faculty of Medicine, Al-Azhar University Cairo, Egypt.

Disclosure: The authors have no financial interest to declare in relation to the content of this article. The Article Processing Charge was paid for by the authors.

Authorship: All authors have a substantial contribution to the article.

\begin{abstract}
Background: A missed miscarriage represents a form of spontaneous abortion, it occurs in about $26 \%$ of all pregnancies and the management may be expectantly, surgical, and medical. Misoprostol and letrozole are medications utilized for medical treatment of miscarriages.

Aim of the work: to match the security and effectiveness of two treatment modalities (Misoprostol versus Letrozol with Misoprostol) in medical treatment of 1st trimesteric missed miscarriages.

Patients and methods: This is an interventional randomized casecontrol investigation that was performed at the outpatient antenatal care clinic of Luxor General Hospital during the period from February to December 2017. The study included a number of 200 cases who have been randomly classified to 2 equal groups: Group-I "Misoprostol" which included 100 cases received $800-\mathrm{mg}$ of misoprostol vaginally at once of diagnosis and group-II "Letrozol + Misoprostol" which included 100 cases received 10-mg letrozol 2 times a day for 3-days as pretreatment then $800-\mathrm{mg}$ of vaginal misoprostol.

Results: Misoprostol alone group (group-I) has a significantly high duration of vaginal bleeding after the 1st Misoprostol dose and time passed after 1st misoprostol dose till the 1st passage of POC in comparison with group-II, (P-value $<0.01$ for all). Misoprostol alone group had significantly higher incomplete abortion $(\mathrm{P}<0.01)$ and emergency $\mathrm{D}$ and $\mathrm{C}(\mathrm{P}=0.03)$ in comparison with the combined group (group-II). However, induction of abortion interval was significantly high in Letrozol + Misoprostol group in comparison with Misoprostol alone group $(99.4 \pm 14.3$ vs. $61.5 \pm 13.2 \mathrm{hrs}, \mathrm{P}<0.01)$.

Conclusion: The results revealed that a 3-days course of letrozole (10mg per day) trailed by misoprostol vaginally (800-mg) was accompanied with a significantly high full abortions rate in women with first-trimester miscarriage compared to misoprostol alone ( $81.0 \%$ vs. $54.0 \%)$ without increasing side effects.
\end{abstract}

Keywords: Misoprostol; Letrozol; Management; First Trimesteric; Missed Miscarriage.

\section{INTRODUCTION}

Abortion is the gestation terminations earlier to a fetus can potentially live outside the uterus, it is a mutual complication of gestation occurring either spontaneously (miscarriage) or on purpose (induced abortion). ${ }^{1}$ A missed miscarriage happens in 10 to $20 \%$ of the clinical recognized gestations. ${ }^{2}$ Between 1990 and 1994, it was estimated that about 50 million induced abortions occurred per year worldwide while, this number increased to 56 million per year during the period from 2010 to $2014 .^{3}$ Also, it was estimated that about $50 \%$ of abortions are not safe and could cause considerable maternal deaths therefore, successful management of abortion is a crucial matter in gynecology.

Vacuum aspiration surgery was the selected method for terminating pregnancy in 1960 s, then persuading abortions using medications is vastly utilized in worldwide levels via mifepristone manufacture. ${ }^{5}$ Persuading abortions via medications is a substitute for surgical treatment, which has economy profits with lower side-effects and its success rate is 60 to $95 \%{ }^{6}$ Several medications can be utilized to persuade abortions and counting limitations in access to mifepristone medications and its high price, it isn't available in the majority of the republics and substitute medications are utilized to persuade abortions. ${ }^{7}$ One of these medications is misoprostol which is prostaglandin E1 analogue.

Misoprostol is a prostaglandin that reasons myometrial cervical softening, contractions, and dilatations and it is utilized to persuade abortions and labour and to manage atonic postpartum hemorrhage and peptic ulcers. ${ }^{4}$ It has the benefit of being economic and steady with a low rate of sideeffects, which has result in it has been comprised in the WHO list of important medications. ${ }^{6}$ In addition, misoprostol is could be kept in room temperature, it is affordable and efficient, doesn't need special care 
during use and usually used with different routes of administration "vaginally, orally and sublingual". ${ }^{1}$ Also, misoprostol is well tolerated by cases and significantly decreases treatments prices in addition, it considerably reduces curettage and the need for surgical intervention. ${ }^{5}$

Letrozole is a key aromatase inhibitor, that is utilized to excite ovulations in non-fertile females suffered from ovulatory dysfunctions, it has a comparatively short 45 -h half-life and it is active orally and inhibits aromatase enzymes oppositely. ${ }^{8}$ Letrozole can have a function in abortions therapies by constraining estrogen synthesis that causes rise endogenous gonadotropin and lastly excites the growing of ovaria's follicles. ${ }^{9}$ As well, it has been reported that Letrozole is also used for the treatment of breast cancer related to estrogen and it can replace mifepristone "which is expensive and not available in many countries". ${ }^{10}$

Some researchers propose prescriptions of aromatase inhibitors before the usage of major medication "such as misoprostol or mifepristone" for persuading medication abortions rises effectiveness of management regimens and also decreases the necessity for surgery. ${ }^{9}$ A success rate of $86.9 \%$ was achieved when letrozole was managed for 3-days trailed by misoprostol. ${ }^{11}$ In another study, letrozole protocol has been utilized for 7-days and attained 95 $\%$ rate of success. ${ }^{9}$ While, letrozole and mifepristone were managed before misoprostol and accomplished a rate of complete abortion $98 \% .^{10}$ Many studies evaluated the impact of misoprostol with letrozole in management of missed miscarriage, but reaching firm results need further studies. The objective of this work was to match the safety and effectiveness of two treatment modalities (Misoprostol versus Letrozol with Misoprostol) in medical treatment of the $1^{\text {st }}$ trimesteric missed miscarriages.

\section{PATIENTS AND METHODS}

This is an interventional randomized case-control research that has been performed at the outpatient antenatal care clinic of Luxor General Hospital during the period from February to December 2017. The study included a number of 200-cases who were randomly classified to 2 equal groups: Group-I "Misoprostol" which included 100 cases received 800-mg of misoprostol at once of diagnosis vaginally and group-II "Letrozol + Misoprostol" which included 100 cases received $10-\mathrm{mg}$ letrozol 2 times a day for 3 days as pretreatment then $800-\mathrm{mg}$ of vaginal misoprostol. All females with $1^{\text {st }}$ trimester missed miscarriages and closed cervix and no conceptions of products in the cervical duct were included in this work. Exclusion criteria were; preceding attempts for termination of pregnancy, IUCD in utero, uterine tumors such as fibroids or malformations in addition to medical disorders such as heart disease, renal, liver disease and hemorrhage or blood disease.

All included cases have been exposed to the following full history taking counting personal history, complaint and present history, menstrual history, family history, history of medical disorders and full obstetric history. In addition, general, pelvic, abdominal and ultrasonographic examinations were done. Some investigations were done especially, $\mathrm{ABO}$ and $\mathrm{Rh}$, sure diagnosis of missed miscarriage and gestational age by ultrasonography if there is a difference between amenorrhea and gestational age by ultrasound gestational age is recorded.

The first group (Misoprostol group) received 800-mg misoprostol (Misotac, Tab. $200 \mathrm{mcg}$ Sigma ®, Egypt) vaginally at the first day of enrollment in the study and the second group (Letrozol + Misoprostol group) taken 10-mg letrozole (Femara Tab. 2.5-mg, Novarts ${ }^{\circledR}$, Egypt) 2 times a day for 3-days then 800$\mathrm{mg}$ vaginal misoprostol. Patients were advised to document the following; date of $1^{\text {st }}$ vagina blood loss, date of $1^{\text {st }}$ passing of tissues parts, occurrence of pains and its strength (mild, moderate or severe) occurrence of bleeding and its strength (mild, moderate or severe) and its period, occurrence of side effects (nausea, vomiting, hyperpyrexia, shivering, colics etc...). Also, they were recommended to come back to the clinic if there were severe pains and blood loss, intolerable side-effect and at $3^{\text {rd }}$ and $7^{\text {th }}$ day after misoprostol dose. At the $3^{\text {rd }}$ day, ultrasound was done for the detection of incomplete abortion complete and second dose of misoprostol was given if missed or incomplete miscarriage. At the $7^{\text {th }}$ day, ultrasound was done and evacuation was done of missed or incomplete miscarriage. The patient was considered to have incomplete abortion if the remnant inside the uterus $2 \mathrm{~cm}$ or more. Regarding the taken outcome measures, primary outcome measures include full abortions rate and inductions to abortions period. While, the secondary result measures are duration of bleeding, occurrence of side-effects and the need of emergency evacuation.

Statistical analyzing have been done via SPSS-20 program (IBM, NY, USA). ${ }^{2}$ Data are presented as means \pm SD for quantitative data and by No. (\%) for qualitative data. Comparison among groups have been done using Student's t testing for parametric data and using Mann Whitney testing for nonparametric data. Chi-Square testing was utilized to examine the significance among studied groups concerning qualitative data or Fisher exact testing when needed. Probability value (P-value) was supposed significant if $<0.05$ and high significance if it was $<0.01$.

\section{RESULTS}

The present results showed that nonsignificant changes were found among groups regarding ages $(\mathrm{P}$-value $=0.48), \mathrm{BMI}(\mathrm{P}$-value $=0.62)$, gestational age $(\mathrm{P}=0.32)$, gravidity $(\mathrm{P}=0.84)$ and previous $\mathrm{CSs}$ $(\mathrm{P}=0.83)$, (Table, 1). Misoprostol alone group (group, I) had significantly higher time passed after $1^{\text {st }}$ misoprostol dose till the start of vaginal spotting compared to group-II $(53.9 \pm 14.2$ vs. $33.4 \pm 7.4 \mathrm{hrs}$., P-value<0.01). Also, group-I had a significantly higher duration of vaginal bleeding after the $1^{\text {st }}$ misoprostol dose and time passed after $1^{\text {st }}$ misoprostol dose till the $1^{\text {st }}$ passage of POC in comparison with group-II, ( $\mathrm{P}<0.01$ for all), (Table, 2). The results showed that group-I had a significantly higher number of cases needed for 
urgent evaluation due to severe pain or bleeding compared to group-II, ( 22 cases vs. 10 cases) and there was a high statistically significant change among groups as regards following-up $(\mathrm{P}<0.01)$, (Table, 3). Nonsignificant change was found among groups in regard to the occurrence of side effects (37 patients in group-I vs. 32 patients in group-II, (Pvalue $=0.46)$, but nausea and vomiting were significantly prevalent in group-II $(\mathrm{P}<0.01)$, (Table, 4 \& Figure 1). Also, the results indicated that Letrozol + Misoprostol group (group, II) had a significantly high rate of success of full abortions as comparison with Misoprostol only group (group, I) $(81.0 \%$ vs. $54.0 \%, \mathrm{P}<0.01$ ), group-I had a significantly higher incomplete abortion $(\mathrm{P}<0.01)$ and emergency $\mathrm{D}$ and C $(\mathrm{P}=0.03)$, compared to group-II, (Table, $5 \&$ Figure 2). Furthermore, letrozol + Misoprostol group (group-II) had significantly higher induction of abortion into intervals compared to Misoprostol group (group-I), $(99.4 \pm 14.3$ vs. $61.5 \pm 13.2 \mathrm{hrs,}$ $\mathrm{P}<0.01)$.

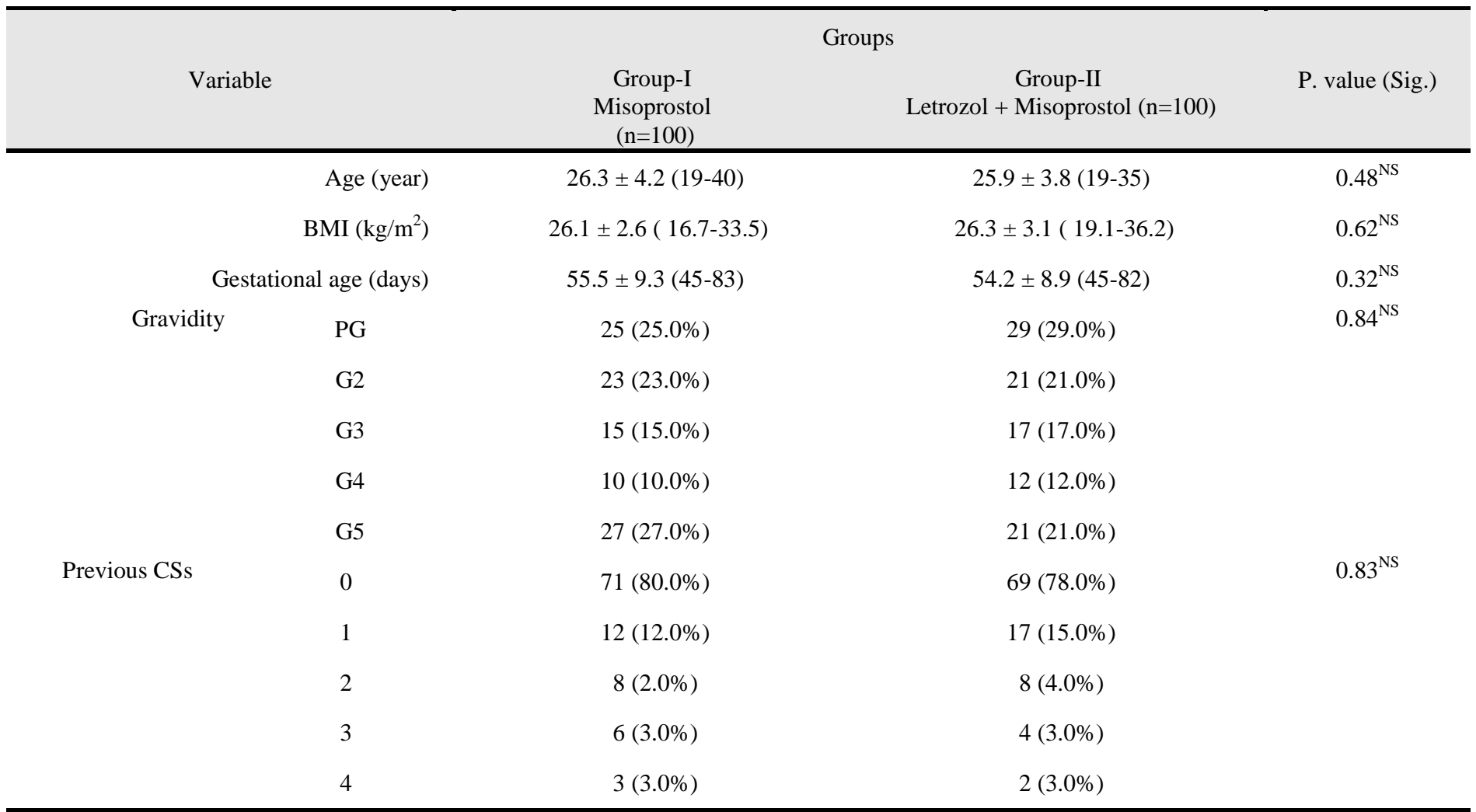

$\mathrm{T}$ testing and Chi-square tests have been utilized to compare between groups.

NS Not significant.

Table 1: Comparison between groups as regard demographic and baseline data.

\begin{tabular}{|c|c|c|c|}
\hline $\begin{array}{r}\text { Time passed after } 1^{\text {st }} \text { misoprostol dose till the } \\
\text { start of vaginal spotting (hrs.) }\end{array}$ & $53.9 \pm 14.2$ & $33.4 \pm 7.4$ & $<0.01 * *$ \\
\hline $\begin{array}{r}\text { Duration of vaginal bleeding after the } 1^{\text {st }} \\
\text { misoprostol dose (hrs.) }\end{array}$ & $72.8 \pm 21.4$ & $36.2 \pm 11.7$ & $<0.01 * *$ \\
\hline
\end{tabular}

** Significance at $(\mathrm{P}-$ value $\leq 0.01)$

Table 2: Comparison between groups as regard clinical findings. 


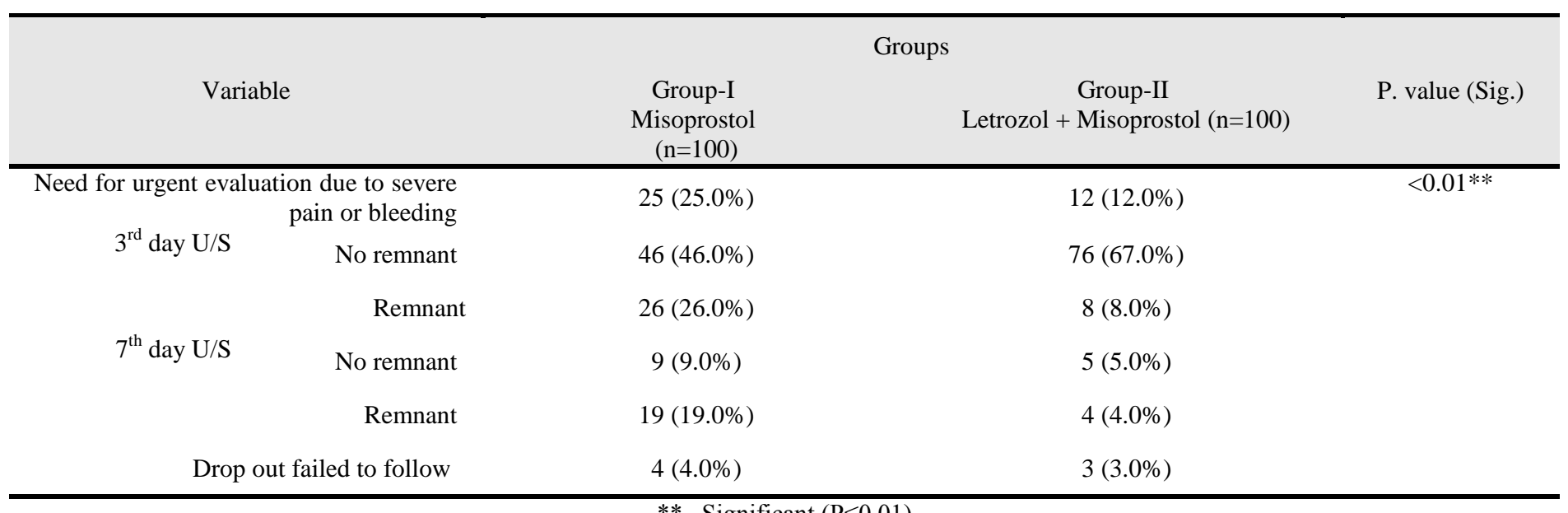

** Significant $(\mathrm{P} \leq 0.01)$

Table 3: Comparison between groups as regard follow-up.

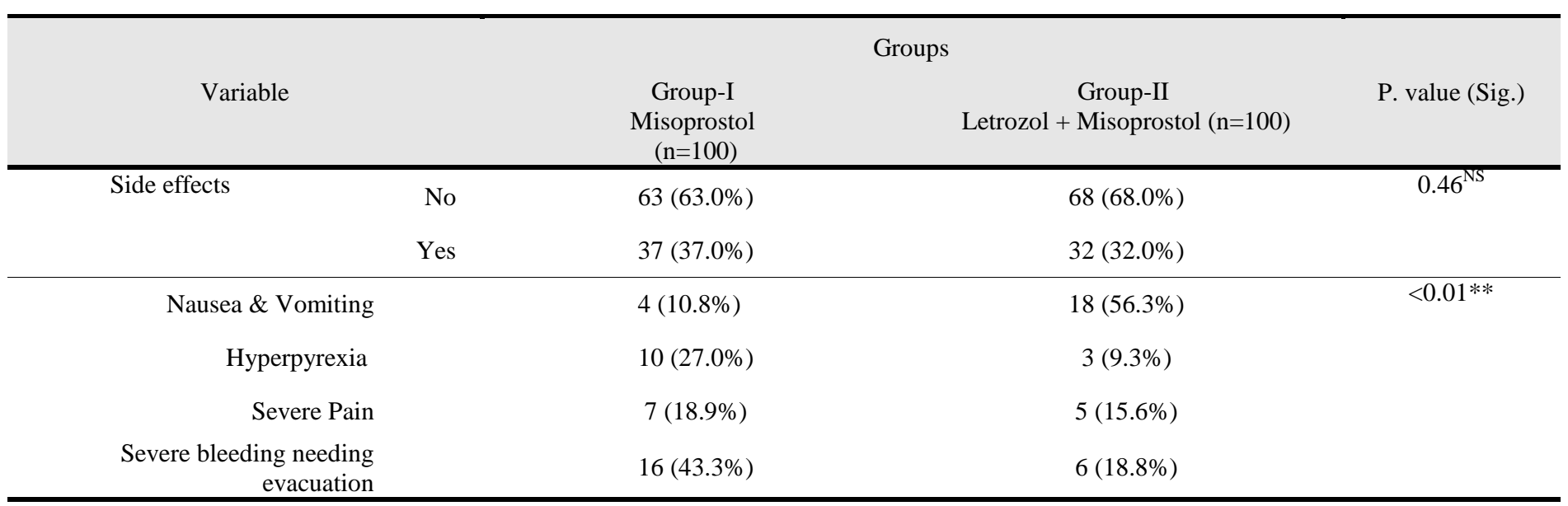

** $\quad$ Significant $(\mathrm{P} \leq 0.01)$

Table 4: Comparison between groups as regard side effects.

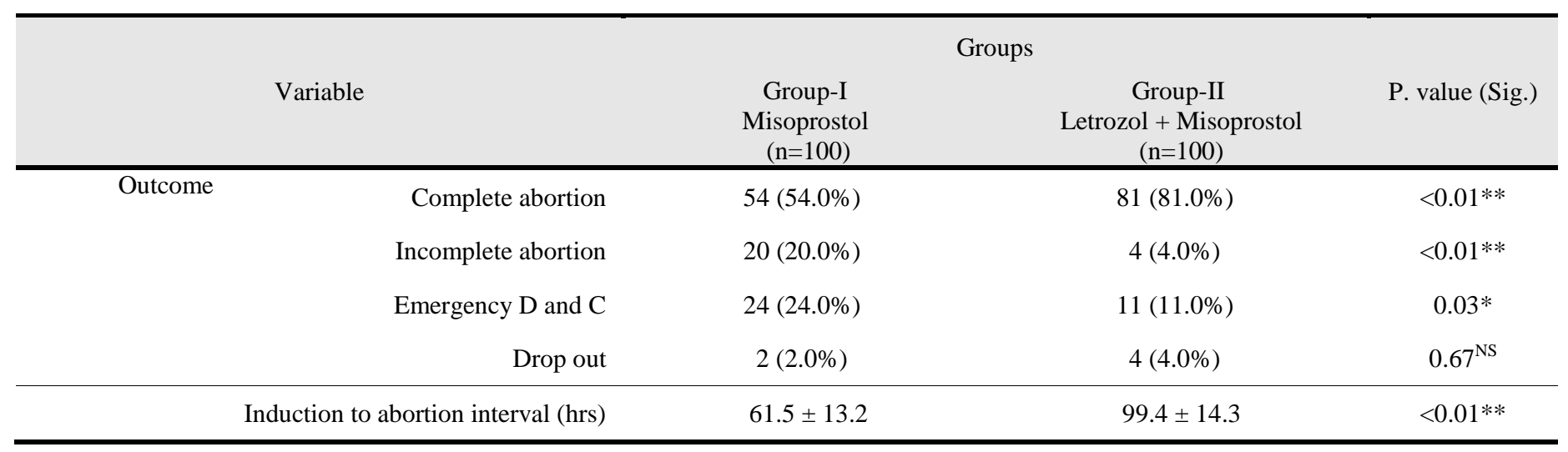

Table 5: Comparison between groups as regard outcome and induction to abortion interval. 


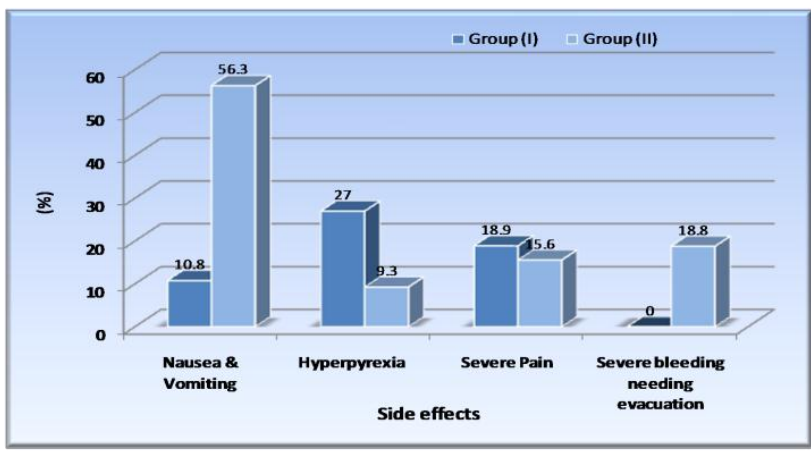

Figure 1: Side effects between groups.

\section{DISCUSSION}

A missed miscarriage represents a form of spontaneous abortion, it occurs in about $26 \%$ of all pregnancies and it can be managed expectantly, surgically, and medically. ${ }^{2}$ Many medications were used for medical treatment of missed miscarriages, Misoprostol and Letrozole are of these medications. In the current work, we aim to compare the safety and efficacy of 2 treating options in the medical managements of the $1^{\text {st }}$ trimesteric missed miscarriage, the first was Misoprostol alone (800-mg of misoprostol at once of diagnosis vaginally) and the second was Letrozol + Misoprostol (10-mg letrozol 2 times a day for 3 days as pretreatment then $800-\mathrm{mg}$ of vaginal misoprostol).

The present results revealed that there were nonsignificant changes among groups regarding ages ( $\mathrm{P}$-value $=0.48)$, BMI $(\mathrm{P}-\mathrm{value}=0.62)$, gestational age $(\mathrm{P}=0.32)$, gravidity $(\mathrm{P}=0.84)$ and previous caesarean sections $(\mathrm{P}=0.83)$. These non-significant differences between studied groups regarding baseline characteristics are important to ensure the homogenization of the studied groups to get accurate results from the comparison between them. These results are in accordance with Naghshineh et al. ${ }^{4}$, Abbasalizadeh et al. ${ }^{5}$, Torky et $\mathrm{al}^{13}$.

The current results demonstrated that Misoprostol alone group had significantly higher number of cases needed urgent evaluation "due to severe pain or bleeding" compared to Letrozol + Misoprostol group (22 cases vs. 10 cases). Similar to our findings, Abbasalizadeh et al. 5 compared the use of misoprostol with or with no Letrozole in inducing abortions. They revealed that $18.8 \%$ of cases in Misoprostol alone group needed surgical curettage versus $6.3 \%$ in Letrozole + Misoprostol group. Also, similar findings were reported by Lee et al. ${ }^{11}$, Naghshineh et al. ${ }^{4}$, Javanmanesh et al. ${ }^{1}$.

Currently, nonsignificant change was noticed among groups in regard to the occurrence of side effects (37 patients in group-I vs. 32 patients in group-II, Pvalue $=0.46$ ), but nausea and vomiting were significantly prevalent in group-II $(\mathrm{P}$-value $<0.01)$. This is in consistent with Torky et al. ${ }^{13}$ who found a higher rate of nausea and vomiting in letrozole + Misoprostol group compared to Misoprostol alone group $(17.0 \%$ vs. $3.0 \%, p=0.002)$. However, they found that the occurrence of other complications

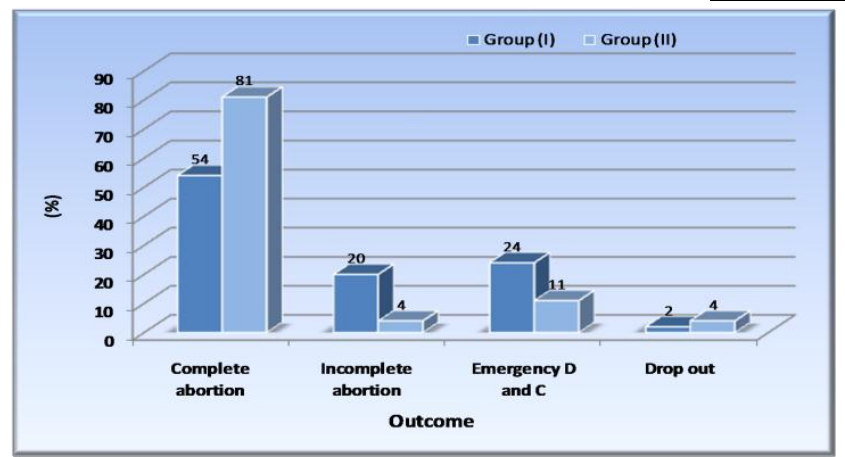

Figure 2: Outcome between groups.

(fever, severe pain and severe bleeding) didn't change significantly among groups. Also, Javanmanesh et al. ${ }^{1}$ found that there was nonsignificant change among Letrozole and Misoprostol groups in regard to adverse effects. Furthermore, Naghshineh et al. ${ }^{4}$ found that sideeffects occurrence and severity were comparable between Misoprostol alone group and Letrozole + Misoprostol one $(\mathrm{P}=0.9)$. Also, Lee et al. ${ }^{11} \&$ Sharami et al. ${ }^{14}$ found similar results. Currently, the significantly higher rates of nausea and vomiting in the combined group can be clarified by the elevated risk of developing side-effects when utilizing 2 medications ${ }^{15,16}$. On the other hand, Abbasalizadeh et al. $^{5}$ found that side effects of Letrozole + Misoprostol were significantly low in comparison to that of Misoprostol only ( $\mathrm{p}$-value $=0.013)$.

The present results indicated that the combined group had a significantly high rate of success of full abortions in comparison with Misoprostol only group ( $81.0 \%$ vs. $54.0 \%, \mathrm{P}<0.01)$. Also, Misoprostol only group had a significantly higher incomplete abortion $(\mathrm{P}<0.01)$ and emergency $\mathrm{D}$ and $\mathrm{C}$. These results are in agreement with Torky et al. ${ }^{13}$ who found that Letrozole + Misoprostol achieved a success rate of $78.0 \%$ in complete miscarriage versus a success rate of $39.0 \%$ that was achieved by Misoprostol alone $(\mathrm{P}<0.01)$. Also, the incomplete miscarriages rate was significantly higher in Misoprostol only group compared to the combined one $(61.0 \%$ vs. $22.0 \%$, $\mathrm{P}<0.01)$. Similarly, Javanmanesh et al. ${ }^{1}$ compared the use of Misoprostol with or with no Letrozole in management of miscarriage. They found that the rate of success was significantly high in the group received Letrozole+ Misoprostol than that of the group receiving Misoprostol only (78.3\% vs.13.0\%; $\mathrm{p}=0.001$ ). Likewise, Abbasalizadeh et al. ${ }^{5}$ found that the rate of full abortions in combined the group (letrozole + Misoprostol) was $93.75 \%$ versus $68.75 \%$ in Misoprostol only group $(\mathrm{p}=0.001)$. Also, they found that number of cases who didn't have full abortion in the combined group was significantly lower compared to misoprostol group (6.3\% vs. $31.5 \%, \mathrm{p}=0.001)$. Additionally, another trial by Behroozi-Lak et al. ${ }^{17}$ revealed that using Letrozole before Misoprostol increases the full abortions rate and decreases the induction-abortion interval in women with a gestational age of $<14$ weeks "which also agreed with our findings". Also, Naghshineh et al. $^{4}$ reported that letrozole + Misoprostol achieved a 
complete abortion rate of $76.7 \%$ in comparison to $42.6 \%$ using Misoprostol alone $(\mathrm{P}<0.001)$. Furthermore, Lee et al. ${ }^{11}$ reported that the administration of Letrozole for 3 days followed by misoprostol achieved a higher rate of success of complete abortions versus Misoprostol alone (86.9\% vs. $72.6 \%)$.

In a report that tried to find out the mechanism of Letrozole in inducing abortion, Lee et al. ${ }^{18}$ reported that Letrozole suppressed the expression of progesterone receptor transcripts, estrogen receptoralpha and estrogen receptor- $\alpha$ protein in the placentas of cases taking it. Furthermore, Lee et al. ${ }^{19}$ evaluated the influence of Letrozole on uterine artery Doppler indices earlier to operative terminations of the $1^{\text {st }}$ trimester pregnancies and they revealed that pulsatility as well as resistances indexes decreased significantly in the Letrozole group, that proposes that blood flowing fluctuations may has a function in the mechanism of Letrozole action. Also, Lee et al. ${ }^{11}$ reported that estradiol levels were significantly low afterward Letrozole management in the $1^{\text {st }}$ trimester induction of miscarriage and this proposes that Letrozole can act via suppressing estrogen as well as progesterone receptors. Another explanation, Letrozole was revealed to suppress endothelial growing factor which can has a function in the induction of miscarriage ${ }^{20,21}$.

Finally, this study has some strengths points and limitations, the relatively high number of included participants are from the strengths points. Regarding the limitations, we could not evaluate the effect of different doses of misoprostol with the least effective dose to decrease the adverse effects in addition, we could not evaluate different routes of administration.

\section{CONCLUSION}

In conclusion, a 3-days course of letrozole (10-mg per day) trailed by misoprostol vaginally $(800-\mathrm{mg})$ was accompanied with a significantly high full abortions rates in cases with 1st-trimester miscarriages compared to misoprostol alone $(81.0 \%$ vs. $54.0 \%$ ) without increasing side effects. Further larger researches via various dosages and extended periods can be necessary to find out the best treating protocol to attain the highest rate of success and the lowest side-effects rates.

\section{REFERENCES}

1. Javanmanesh F., M. Kashanian, Sara Mirpangi. Comparison of Using Misoprostol with or without Letrozole in Abortion Induction: A Placebo-Controlled Clinical Trial. Journal of Obstetrics, Gynecology and Cancer Research. 2018;3(2):49-52.

2. Serdinšek, T., Reljič, M., \& Kovač, V. (2019). Medical management of first trimester missed miscarriage: the efficacy and complication rate. $J$. of Obst. and Gyn., 2019; ;4(5): 1-5.

3. 3Sedgh G, Bearak J, Singh S, Bankole A, Popinchalk A, Ganatra B, et al. Abortion incidence between 1990 and 2014: Global, regional, and subregional levels and trends. Lancet. 2016;388(10041):258-67.
4. Naghshineh E, Allame Z, Farhat F. The effectiveness of using misoprostol with and without Letrozole for successful medical abortion: A randomized placebocontrolled clinical trial. $J$ Res Med Sci. 2015;20(6):585-9.

5. Abbasalizadeh F. , F. Sahhaf, P. SadeghiShabestari, Mohammad Mirza-AghazadehAttari, and Mohammad Naghavi-Behzad . Comparison Between Effect of Letrozole Plus Misoprostol and Misoprostol Alone in Terminating Non-Viable First Trimester Pregnancies: A Single Blind Randomized Trial. J Family Reprod Health. 2018; 12(1): 27-33.

6. WHO, (2014): Clinical Practice Handbook for Safe Abortion. Geneva: World Health Organization; 2014.

7. 7Dalenda C, Ines N, Fathia B, Malika A, Bechir Z, Ezzeddine $\mathrm{S}$, et al. Two medical abortion regimens for late first-trimester termination of pregnancy: a prospective randomized trial. Contraception . 2010; 81:323-7.

8. 8Malloch L, Rhoton-Vlasak A. An assessment of current clinical attitudes toward letrozole use in reproductive endocrinology practices. Fertil Steril. 2013;100:1740-4.

9. Yeung $\mathrm{T} \mathrm{W}$, Lee V C, Ng E H. A pilot study on the use of a 7-day course of letrozole followed by misoprostol for the termination of early pregnancy up to 63 days. Contraception. 2012;86:763-9.

10. Chai J, Ho P C. A pilot study on the combined use of letrozole, mifepristone and misoprostol in termination of first trimester pregnancy up to 9 weeks' gestation. Eur J Obstet Gynecol Reprod Biol. 2013;171:291-4.

11. Lee V C, Ng E H, Yeung W S. Misoprostol with or without letrozole pretreatment for termination of pregnancy: a randomized controlled trial. Obstet Gynecol. 2011;117:317-23.

12. IBM Corp.. IBM SPSS Statistics for Windows, Version 20.0. Armonk, NY: IBM Corp. 2011

13. 13. Torky H. A. , H. Marie, E. ElDesouky, S. Gebreel, et al. Letrozole vs. Placebo Pretreatment in the Medical Management of First Trimester Missed Miscarriage: a Randomized Controlled Trial. Geburtshilfe Frauenheilkd. 2018; 78(1): 63-9.

14. Sharami F, SH, Arjmandi S. Comparison of sublingual and vaginal misoprostol for second-trimester pregnancy terminations. $J$ Family Reprod Health. 2014;8:41-4.

15. Von Hertzen H, Piaggio G, Wojdyla D et al. Comparison of vaginal and sublingual misoprostol for second trimester abortion: Randomized controlled equivalence trial. Hum Reprod 2009; 24: 106-12.

16. Von Hertzen H, Huong NT, Piaggio G et al. Misoprostol dose and route after mifepristone for early medical abortion: a randomised controlled noninferiority trial. BJOG .2010; 117: 1186-96.

17. Behroozi-Lak T, Derakhshan-Aydenloo S, Broomand F. Evaluation of effect of letrozole prior to misoprostol in comparison with misoprostol alone in success rate 
of induced abortion. J Gynecol Obstet Hum Reprod. 2018;47(3):113-7.

18. Lee VC, Gao J, Lee KF, Ng EH, Yeung WS, Ho PC. The effect of letrozole with misoprostol for medical termination of pregnancy on the expression of steroid receptors in the placenta. Hum Reprod .2013: 28:29129.

19. Lee VC, Yeung TW, Tang OS et al. Effect of letrozole on uterine artery Doppler flow indices prior to firsttrimester termination of pregnancy: a randomized controlled trial. Ultrasound Obstet Gynecol .2012; 40: 392-7.

20. Albrecht ED, Robb VA, Pepe GJ. Regulation of placental vascular endothelial growth/permeability factor expression and angiogenesis by estrogen during early baboon pregnancy. J Clin Endocrinol Metab . 2004; 89: 5803-9

21. Schiessl B, Innes BA, Bulmer JN et al. Localization of angiogenic growth factors and their receptors in the human placental bed throughout normal human pregnancy. Placenta .2009; 30: 79-87 